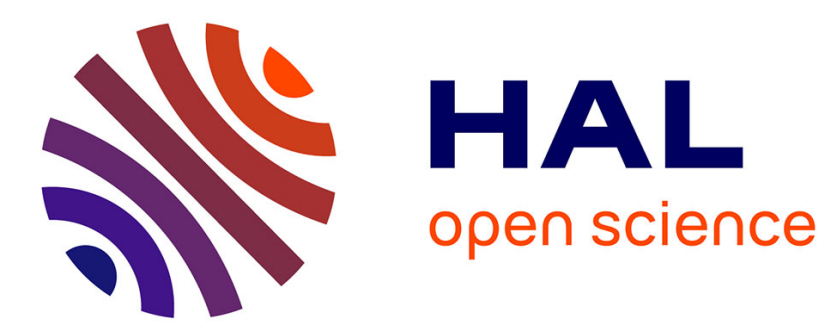

\title{
Gilles de la Tourette syndrome - A treatable condition?
}

\author{
A. Hartmann, D. Martino, T. Murphy
}

\section{To cite this version:}

A. Hartmann, D. Martino, T. Murphy. Gilles de la Tourette syndrome - A treatable condition?. Revue Neurologique, 2016, 172 (8-9), pp.446 - 454. 10.1016/j.neurol.2016.07.004 . hal-01405727

\section{HAL Id: hal-01405727 https: / hal.sorbonne-universite.fr/hal-01405727}

Submitted on 30 Nov 2016

HAL is a multi-disciplinary open access archive for the deposit and dissemination of scientific research documents, whether they are published or not. The documents may come from teaching and research institutions in France or abroad, or from public or private research centers.
L'archive ouverte pluridisciplinaire HAL, est destinée au dépôt et à la diffusion de documents scientifiques de niveau recherche, publiés ou non, émanant des établissements d'enseignement et de recherche français ou étrangers, des laboratoires publics ou privés. 


\section{Gilles de la Tourette Syndrome - a treatable condition ?}

Andreas Hartmann ${ }^{1,2,3}$, MD, Davide Martino, MD, $\mathrm{PhD}^{4,5}$, Tara Murphy ${ }^{6}, \mathrm{PhD}$

1-Sorbonne Universités, UPMC Univ Paris 06, UMR S 1127, CNRS UMR 7225, ICM, F75013, Paris, France

2-Assistance Publique-Hôpitaux de Paris, Department of Neurology, Groupe Hospitalier Pitié-Salpêtrière, 47 boulevard de 1'Hôpital, F-75013, Paris, France

3-French National Reference Centre for Gilles de la Tourette Syndrome, Groupe Hospitalier Pitié-Salpêtrière, 47-83 boulevard de l’Hôpital, F-75013, Paris, France

4- International Parkinson's Centre of Excellence, King's College and King's College Hospital, Denmark Hill Campus, London;

5- Queen Elizabeth Hospital, Woolwich, Lewisham \& Greenwich NHS Trust, London, UK

6- Tourette syndrome Clinic, DCAMH, Great Ormond Street Hospital, London, WC1N 3JH, UK

\section{Correspondence to:}

Andreas Hartmann

French National Reference Centre for Gilles de la Tourette Syndrome

Department of Neurology

Groupe Hospitalier Pitié-Salpêtrière

47-83 boulevard de 1'Hôpital

75013 Paris, France

Email: andreas.hartmann@aphp.fr

Funding sources: AH has received research support from the "Association Française pour le syndrome Gilles de la Tourette" (AFSGT), France Parkinson (Grand Appel d'Offre 2011) and by funding from the program "Investissements d'Avenir" ANR-10-IAIHU-06. 
Key words: Tics, Gilles de la Tourette syndrome, psychotherapy, pharmacotherapy, deep brain stimulation

Abbreviations:

ACT - Acceptance and Commitment Therapy

ADHD - attention deficit hyperactivity disorder

BT - behavioural therapy

CBIT - Comprehensive Behavioral Intervention for Tics

$\mathrm{CM} / \mathrm{Pf}$ - centromedian $(\mathrm{CM}) /$ parafascicular $(\mathrm{Pf})$-substantia periventricularis-nucleus

$\mathrm{CNS}$ - central nerevous system

DBS - deep brain stimulation

ERP - exposure response prevention

ESSTS - European Society for the Study of Tourette Syndrome

FAAH - fatty acid amide hydrolase

GABA - $\gamma$-aminobutyric acid

GPe - globus pallidus externus

$\mathrm{GPi}$ - globus pallidus internus

GTS - Gilles de la Tourette syndrome

HDC - histidine decarboxylase

HRT - habit reversal training

OCD - obsessive compulsive disorder

RCT - randomized controlled trial

STN - subthalamic nucleus

THC - tetrahydrocannabinol

TSA - Tourette Syndrome Association

YGTSS - Yale Global Tic Severity Scale 


\section{Abstract}

Introduction: Gilles de la Tourette syndrome (GTS) is a neurodevelopmental disorder characterized by chronic motor and vocal tics. Psychiatric comorbidity is frequent but does not enter into the official classification of the syndrome. In the present article, we will focus on treatment options for tics.

Methods: We have reviewed the relevant literature on treatment of tics and GTS, especially in the period from 2011-2016 since the publication of the European Society for the Study of Tourette Syndrome (ESSTS) treatment guidelines in 2011.

Results: We present current and up-to-date approaches in psychotherapy, pharmacotherapy and neurosurgery for GTS with an outlook for the upcoming years.

Conclusions: Although many patients and health-care professionals seem to view tics and/or GTS as difficult to treat, or believe that treatment requires severe side effects with reduction in quality of life, we wish to convey that there is cause for optimism, both with regard to available treatment modalities and future therapeutic developments.

\section{Résumé}

Introduction: Le syndrome Gilles de la Tourette (SGT) est un trouble neurodévelopmental caractérisé par la présence chronique de tics moteurs et vocaux. Les comorbidités psychiatriques sont fréquentes mais ne font pas partie de la définition officielle du SGT. Dans l'article présent, nous nous focaliserons sur les traitements anti-tics.

Méthodes: Nous avons analisé la littérature relevante concernant le traitement des tics et du SGT, en particulier couvrant la période de 2011-2016, c'est-à-dire depuis la publication des guidelines de traitement européens par la European Society for the Study of Tourette Syndrome (ESSTS) en 2011. 
Résultats: Nous présentons les approches courantes sur les traitements anti-tics en psychothérapie, pharmacothérapie et neurochirurgie ainsi que les perspectives d'évolution dans ces domaines.

Conclusions: Malgré le fait que nombreux patients et professionnels de santé estiment le traitement des tics et/ou du SGT difficile, ou se focalisent sur les risques et effets secondaires potentiels, nous souhaitons mettre en avant un vision optimiste, aussi bien concernant le présent que les évolutions futures. 


\section{Introduction}

Gilles de la Tourette syndrome (GTS) is a neurodevelopmental disorder characterized by the presence of at least two motor and one vocal tic over a period exceeding one year with onset before the age of 18 years [1]. Psychiatric comorbidities (attention deficit hyperactivity disorder, obsessive-compulsive disorder, autism-spectrum disorder, anxiety, depression and others) are multiple and occur in almost $90 \%$ of cases [2]. Nonetheless, tics remain the conditio sine qua non to diagnose GTS and are generally the reason individuals with tics seek to obtain a diagnosis and treatment. In this review, we will therefore focus on the treatment of tics. For those readers interested in the diagnosis and treatment of comorbidities, we refer to the textbook by Martino and Leckman [3] and a recent review series [4].

For several decades after Gilles de la Tourette's initial description [5], GTS was considered a psychogenic condition and therefore psychotherapeutic, especially psychodynamic approaches were used in trying to reduce tics [6]. In the early 1960s, haloperidol was introduced as a pharmacological agent for tics which also induced a paradigmatic shift, viewing tics primarily as abnormal movements with an organic/cerebral substrate [7]. However, the use of antipsychotics in non-psychotic patients remains a challenge to this day, ensuing a certain therapeutic scepticism if not nihilism both in the affected individual, their families, and their treating physicians. Also, beyond pharmacological approaches, more recent treatment options such as behavioural therapy (BT) and deep brain stimulation (DBS) remain unknown to many patients and health-care professionals [8].

In the present article, we will review major therapeutic advances in these three domains (BT, pharmacology, DBS) since the publication of the European Society for the 
Study of Tourette Syndrome (ESSTS) treatment guidelines [9-12], thus covering mainly the period from 2011-2016, with an outlook for the upcoming years.

\section{When and how do tics need to be treated?}

According to the ESSTS guidelines [10], four reasons should be considered for moving beyond giving psychoeducation to the patient and their system, and proactively treating tics:

1. Tics cause subjective discomfort (e.g. pain or injury)

2. Tics cause sustained social problems for the patient (e.g., social isolation or bullying)

3. Tics cause social and emotional problems for the patient (e.g., reactive depressive symptoms)

4. Tics cause functional interference (e.g., impairment of academic achievements)

As first-line treatment, we would nowadays - depending on availability and financial resources (psychotherapy not being reimbursed in all European countries) - advocate BT. The obvious advantage is the lack of pharmacologically-induced side effects. Also, these interventions provide the individual with a sense of accomplishment not obtained by taking drugs. Lastly, but speculatively, BT might affect the long term course of tic evolution by inducing plastic central nervous system (CNS) changes with a more favourable long term prognosis. Or at least, BT offers the paediatric patient the opportunity to develop a set of skills to cope and live with vocal and motor tics potentially for a decade or more. A second choice of intervention would be pharmacological treatment, either systemic (drugs per os) or local (botulinum toxin), either as stand-alone treatments or as add-on to BT. Lastly, DBS is reserved for patients either refractory to the aforementioned treatment options or responsive but burdened with severe medication-induced side effects.

\section{Psychotherapy}


There have been more than 40 years of research evaluating behavioural treatment for individuals with tic disorders. Most of the early research focused on tic control whereas more recently outcome measures encompass psychosocial wellbeing and daily function given that even the most potent interventions result in only modest tic reduction. In general, the evidence for BT is comparable to the most effective pharmacotherapy treatments [13]. There has been development in the emergence of psychological treatments which are effective, even if the underlying mechanism still remains elusive. Since the European guidelines describing best practice for BT were published [11] there have been developments in the delivery of treatment rather than any drastically new form of treatment.

\section{Behavioural therapy}

All treatments continue to recognise the inclusion of educational information about the aetiology, course, prognosis and commonly co-occurring conditions with GTS which is commonly a first step in the intervention.

Azrin and Nunn [14] developed a program referred to as Habit Reversal Training (HRT) which requires the individual to develop an awareness of a specific tic through tuning in to what is referred to as "premonitory urge", a sensory experience that signals the onset of a tic. In treatment, the individual learns to inhibit the production of the tic when they notice the premonitory urge by applying an incompatible movement or breathing pattern which they must hold until the urge to tic disappears. These tic-blocking behaviours are called 'competing responses'. The technique is taught to a point that it is used automatically so that the individual is able to carry out everyday tasks while they manage the tics and associated urges. Recently, randomised controlled trials (RCTs) have demonstrated significant improvement in tic symptoms following a course of HRT delivered as part of a wider 
program referred to as Comprehensive Behavioral Intervention for Tics (CBIT) with moderate effect sizes in reduction in tics in children [15] and adults [16] post treatment.

Exposure and Response Prevention (ERP) is a similar BT, although less researched, has shown to have good efficacy in tic management in children and adults [17]. In ERP, the individual tolerates exposure to the premonitory urge that precedes the tic whilst suppressing the tic for as long as possible, the time of which is extended during and beyond treatment. The urge is emphasised through the course of treatment. The approach promotes habituation to the urge, reducing the subjective intensity of the premonitory urge. There has been some discussion recently in the literature as to whether the underlying mechanism behind the tolerance of the urge relates to habituation to the sensation or to challenge the belief that the urge and associated tic are locked into a negative reinforcement cycle. Treatment effects of ERP have been found to be comparable to that of HRT (Verdellen et al., 2004) in a small study of adults and children with GTS.

\section{Cognitive-behavioural therapy}

During the 2000s, BT has been extended to include cognitive elements of treatment in which the individual with GTS learns to restructure or reframe negative perceptions associated with tics, particularly in high risk situation [18-20]. Another treatment program 'Living With Tics' $[21,22]$, which employs a modular approach, based on the individual's presenting problem has been evaluated in a small sample and found to show some promise with regards to impairment ratings and anxiety symptoms. The intervention employs cognitive restructuring tools alongside HRT to address distorted beliefs about having tics and the impact the negative thoughts have on the individual's everyday life with the aim of improving quality of life and reducing impairment associated with tics [22]. 


\section{Third wave}

Following the addition of the cognitive elements to BT, has emerged a group of treatments often referred to as "Third wave psychotherapy", an approach which emphasises emotions, mindfulness, dialectics, metacognition, acceptance and spirituality [23]. These developments are in their infancy in the treatment of GTS and to date have been cautiously coupled with HRT and show little demonstrable advantage on tic management. Reese et al. [24] assessed the feasibility of a mindfulness-based stress reduction treatment (MBSR-tics) targeting ticrelated anxiety and frustration in a small group of adults with GTS. Results show improvement in severity and impairment. Another program used a program of adapted HRT which included Acceptance and Commitment Therapy (ACT) to promote acceptance of ticrelated urges [25] in a small group of adolescents.

Despite the evidence-base for behavioural interventions, treatment is not widely available or accessible [22]. This lack of provision has been attributed to a limited awareness and few trained clinicians. To address the limitations of services, several novel treatment delivery approaches have been developed. The simple rules based, highly structured nature of BT has facilitated its adaptation for novel treatment delivery using approaches such as telemedicine [26,27], group treatment, and intensive outpatient treatment rather than traditional weekly sessions. In addition, there has been delivery of treatment by nonpsychologist professionals such as occupational therapists [28], physicians and nurse practitioners [29].

Taken together, the evidence base for BT is fair but there is much room for development. Future research should aim for large, high quality, well designed studies with active comparison conditions, given the waxing and waxing of tics. Limitations to the evidence-base are that existing studies have been recruited in North America, Europe and recently Japan. Outcome measures have slowly started to include a broader remit beyond tic 
severity such as psychosocial function and child-report of quality of life. Many of the studies to date are small pilot or feasibility studies with little replication. Importantly, it will be important to refine and understand the key active mechanisms of change within GTS treatment. Assessment of long term outcome following psychological intervention is not well documented in the literature and offers further potential for understanding the effectiveness of treatment.

\section{Pharmacology}

\section{Antipsychotics}

Antipsychotics, e.g. dopamine receptor antagonists (especially D2 blockers) have been the mainstay in the treatment of tics for half a century now, but with a considerable and ongoing reluctance. Clinicians using these drugs are especially afraid of extrapyramidal side effects, e.g. tardive dyskinesias. Therefore, in North America, first-line pharmacologic treatment of tics remains focussed on clonidine, an alpha-2-receptor agonist, or tetrabenazine, a presynaptic dopamine depletor [30]. European clinicians have a different stance on the subject as reviewed by Rickards et al. [31], favouring antipsychotics as first line treatment of tics, but with moderate enthusiasm nonetheless. Of note, a recent case review [32] on 521 adult GTS patients treated with antipsychotics supports the notion that they are not prone to tardive dyskinesia but seem rather "protected" against those, which, in our experience, also seems to hold true for paediatric patients. In general, antipsychotic dosages used to treat tics are much lower than treatment for psychotic patients. In practice, we feel that if tics require treatment, the most effective treatment should be offered first line, e.g. antipsychotics, whereas nondopaminergic drugs should rather be used as second line or add-on treatments [33]. Of note, alpha-2-receptor agonists are effective on tics only in patients with GTS and co-morbid ADHD [34]. 
Among antipsychotics, the best evidence is still available for haloperidol, pimozide and risperidone. In certain countries, benzamides such as tiapride and sulpiride are also frequently employed, based on the premise that they cause less sedation and weight gain than typical antipsychotics. Over the last decade though, aripiprazole has become the drug of choice both in pediatric and adult patients with GTS [35]. Aripiprazole has a unique mechanism of action as it is a partial D2 and 5-HT(1A) receptor agonist and a 5-HT(2A) receptor antagonist. It is considered a dopamine "stabilizer" as it displays an antagonistic action in the mesolimbic pathway but an antagonistic action in the mesocortical pathway, thereby normalizing dopaminergic transmission regardless of the type of imbalance [36]. In clinical practice, it is highly effective in reducing tics with lower rates of sedation and metabolic disturbances than typical antipsychotics. Recent studies in children and adolescents [37,38] have confirmed this clinical impression although we still recommend to check regularly, at least annually, for endocrine disturbances (note that aripiprazole decreases prolactine levels in contrast to other neuroleptics) and body mass index changes [39]. Also, based on personal experience, very low dosages ranging between 1.0-2.5 mg per day are often sufficient to control tics in children and even adults. For the latter, $5 \mathrm{mg}$ per day is the usual dosage. Ramping this up to 10 or $15 \mathrm{mg}$ daily sometimes helps but we do not observe a clear dose-response relationship in terms of therapeutic effects. In case aripiprazole does not offer adequate tic control, we usually first revert to typical (pimozide) or atypical (risperidone) antipsychotics or tetrabenazine (see above). An interesting alternative to tetrabenazine might emerge in the form of NBI-98854, a vesicular monoamine transporter 2 inhibitor already tested for the treatment of tardive dyskinesia and currently evaluated both in adult (ClinicalTrials.gov NCT02581865) and paediatric (ClinicalTrials.gov NCT02256475) patients with GTS. 
Traditonally, antipsychotics used to treat tics block D2 receptors as they are mainly involved in the indirect pathway of the motor cortico-striatal-thalamo-cortical (CSTC) circuits. Comparatively, D3/D4 receptor blockers (olanzapine, clozapine, quietapine), more present in limbic portions of the CSTC circuits, appear of limited efficacy in treating tics. D1 receptor blockers have so far been unavailable to target the direct pathway of the motor CSTC circuits. Recently, however, an open-label trial investigating ecopipam, a selective D1 antagonist, has reported encouraging results in treating tics [40]. Consequently, a phase 2 randomized controlled trial using ecopipam has been registered and is currently recruiting paediatric GTS patients (ClinicalTrials.gov NCT02102698).

In case of partial but insufficient response to antipsychotics, another strategy involves adding a nondopaminergic drug, for instance levetiracetam, topiramate, clonazepam or baclofen. Among these, we favour topiramate as having the best evidence [41]. We will also mention the use of botulinum toxin, both in peripheral muscles for single, isolated tics, and in the vocal cords for disabling vocal tics as helpful stand alone of add-on treatment [42].

\section{Cannabis}

A strong candidate for tic reduction is cannabis, both based on clinical observations and studies performed in the early 2000s [43]. The availability of pharmaceutical grade cannabis products, especially tetrahydrocannabinol (THC) remains very limited but the situation might evolve over the next years, partly due to the introduction of cannabis-derived products to treat a variety of conditions such as spasticity, pain and appetite loss [44]. For instance, Sativex ${ }^{\circledR}$ (a buccal spray that contains THC and cannabidiol in a $1: 1$ ratio) has recently been introduced in several European countries for the treatment of spasticity in multiple sclerosis and will likely be tested in large randomized clinical trials in patients with GTS in the foreseeable future (K. Müller-Vahl, personal communication). Another way to target the 
cannabinoid system is to raise endocannabinoid (anandamide and 2-arachidonoyl glycerol) concentrations. An inhibitor of the main anandamide-metabolising enzyme, fatty acid amide hydrolase (FAAH) is currently being investigated in adult patients with GTS patients (ClinicalTrials.gov NCT02134080).

\section{New targets}

Overall, with regard to new pharmacologic treatments of tics, the past decade has seen little innovation except for the introduction of aripiprazole and the promises of THC. Nonetheless, the future appears brighter for patients with GTS than it used to be for two reasons. First, the recognition that GTS is not as rare as previously believed: recent meta-analyses point to a prevalence of $0.5 \%$ in the paediatric population [45]. As a consequence, both institutional and industry-driven research is picking up pace. Second, our understanding of GTS has deepened over the last decade, pointing to neurotransmission systems other than dopamine to be targeted. Among these feature most prominently acetylcholine, GABA, glutamate, and histamine.

Based on seminal postmortem work showing a loss of GABAergic and cholinergic interneurons in the striatum of patients with GTS $[46,47]$ and possibly also in cortical areas, increasing GABAergic and cholinergic neurotransmission to treat tics is pathophysiologically plausible. Indeed, for GABA, both clonazepam and baclofen have been used in the past, with tangible but limited success so far [33]. Acetylcholinesterase inhibitors have also been tried in small cohorts and appear promising albeit for the fact that they seem to be poorly tolerated [48]. Nonetheless, individual dosages could be reduced by combining drugs to target several neurotransmitter systems simultanously [49]. Moreover, the development of better tolerated and/or safer (especially with regard to addiction) drugs is a distinct possibility. For instance, finasteride is a 5alpha-reductase inhibitor that received clinical approval for the treatment of 
human benign prostatic hyperplasia and androgenetic alopecia. In the CNS, 5alpha-reductase is the enzyme catalysing the key rate-limiting step in the synthesis of pregnane and androstane neurosteroids. Accordingly, finasteride produces steroid metabolites with rapid non-genomic effects on brain function and behavior, primarily via an enhancement of GABA neurotransmission, with a plausible action on tic reduction in animal models of GTS [50] and a promising preliminary clinical study [51].

Glutamate as an excitatory neurostransmitter has also been declared a potential target for the treatment of tics although evidence for whether its action is increased or decreased in GTS is conflicting [52]. Therefore, studies aiming to either inhibit (riluzole) or stimulate (Dserine) glutamate neurotransmission have been initiated in children; first results were negative but the number of patients was small [53]. In the same vein, a trial with $\mathrm{N}$-acetylcysteine, as an antioxidant and glutamate-modulating agent, has recently been completed although the results remain unpublished (ClinicalTrials.gov NCT01172288). Finally, a new formulation of acamprosate (SNC-102), usually used to treat alcohol addiction, is currently ongoing in adult GTS patients (ClinicalTrials.gov NCT02217007). Acamprosate is known to decrease brain glutamate, modulates N-methyl-d-aspartic acid receptor transmission and may have indirect affects on GABA-A receptor transmission.

The "new kid on the block" in GTS is histamine [54]. Deficiency in histidine decarboxylase (HDC), the rate limiting enzyme in histamine synthesis, has been implicated in familial forms of GTS [55,56] and animal models [57] have pointed to a relevant role of decreased histamine transmission in tic genesis. Pitolisant, a H3 reverse antagonist, is now being marketed for the treatment of narcolepsy [58] and has been tried once in a GTS patient [59]. This seems a promising candidate not only for tic reduction but also comorbid ADHD [60]. Two further H3 reverse antagonist are listed on ClinicalTrials.gov as undergoing or 
having undergone clinical testing in GTS, AZD5213 (ClinicalTrials.gov NCT01904773) and PF-03654746 (ClinicalTrials.gov NCT01475383)

\section{Surgery}

\section{Patient selection}

Over the last 10 years, there has been increasing experience and experimental evidence of the efficacy and tolerability of functional neurosurgery, in particular of DBS, for individuals with GTS. In 2015 the International DBS Database and Registry Study Group endorsed by the Tourette Syndrome Association (TSA) of the USA has published an update on the recommendations for the treatment of GTS with DBS, including about 120 patients since 1999 worldwide [61]. Recommended selection criteria have been proposed (Box 1), which should include, amongst others, a DSM-5 diagnosis of GTS confirmed by a team of expert clinicians, high level of disability primarily caused by tics, a refractoriness to less invasive treatments, clinically stable psychiatric co-morbidities, and reliable social support to guarantee a safe post-operative monitoring. This study group also proposed a definition of refractoriness to conservative treatment which included a previous trial with three different classes of anti-tic medication (which should include one first and one second generation antipsychotic, as well as an $\alpha_{2 \mathrm{~A}}$ adrenergic agonist), and at least the option of offering a course of behavioural therapy. In addition, a particular emphasis was given to the exclusion of patients with self- or heterodirected harmful ideation or possible psychogenicity, further supporting the importance of multidisciplinary evaluation of patients within a specialized team with longstanding experience in GTS [62], in which tics may cause bodily harm, e.g. ‘whiplash' tics generating a risk of post-traumatic cervical myelopathy. 


\section{Update on evidence of efficacy}

International guidelines on the preferable anatomical DBS target in GTS are still lacking, and the main reason for this limitation is the lack of active comparator trials. Approximately 80$85 \%$ of all patients with GTS with documented DBS were operated either on the centromedian $(\mathrm{CM}) /$ parafascicular $(\mathrm{Pf})$-substantia periventricularis-nucleus ventralis oralis internus crosspoint of the thalamus or the globus pallidus pars interna (GPi), with larger experience available when the antero-medial, or limbic, portion of the GPi is targeted.

The CM/Pf nuclei of the thalamus are the most explored target, with more than 70 cases reported. This nuclear complex influences motor and limbic circuits of the cortico-basal ganglia circuitry via a feed-forward mechanism that involves cholinergic striatal interneurons. Two randomized trials, one with parallel design [63] and one with cross-over design [64], both with a post-randomisation open-label phase, showed variable efficacy of bilateral CM/Pf stimulation across subjects but promising group differences pointing to a $37-50 \%$ improvement of tic severity that was sustained at follow-up. Results on the effect of comorbidities, recorded as secondary outcome measures, have been mixed.

The GPi is the main output station of the basal ganglia, hypothesized to be hypoactive in tic disorders. The largest to date randomized controlled trial targeting this region [65] was a crossover study that enrolled 13 patients, 11 stimulated in the limbic GPi and 2 in the motor GPi; each phase lasted 12 weeks and there was a post-randomisation open label phase. The mean proportional difference in YGTSS scores between the on-stim and off-stim conditions was $15.3 \%$, corresponding to 12.4 points on the score. There were more consistent improvements during open-label stimulation adjustment. Progressive increase in amplitude of stimulation and number of active contacts was necessary over time, because suboptimum stimulation parameters were used in the blinded phase of the trial to guarantee masking. Interestingly, stimulation through the most dorsal contacts was associated with optimum tic 
reduction, suggesting that stimulation of the globus pallidus externus (GPe) could also be involved. The largest open label series of limbic GPi stimulation came by Sachdev et al. [66] on 17 individuals followed up for a period ranging between 4 and 30 months; they observed tic reduction by $48-57 \%$ in 10 of them, and some collateral symptom reduction on obsessivecompulsive and depressive symptoms.

Amongst other targets documented in open label series, the anterior limb of the internal capsule and the nucleus accumbens have been used as targets for medically refractory obsessive-compulsive disorder, but in patients with GTS improvements have been very mixed, and mostly on the modest side. The group in Milan led by Servello and Porta used these targets as a 'rescue' procedure in patients whose tics improved with thalamic stimulation but were still troubled by obsessive-compulsive symptoms: interestingly, in almost all of these cases the rescue DBS did not objectively improve OCD but led to further improvements in their tic scores [67-69]. More research is needed on this target. Only isolated but positive experiences targeting the GPe [70] and the subthalamic nucleus (STN) [71] have been reported. The hypothesis of using the anterior STN or GPe as a potential target to treat the different manifestations of the complex GTS spectrum was suggested by data on the effect of this stimulation on the stereotyped behaviour of primate animal models [72].

\section{Safety}

DBS may lead to general, surgery-related complications that apply to all anatomical targets and indications, e.g. hemorrhage and infection of the electrode implant site. Whereas only a limited number of mechanical problems leading to breakage of lead connectors or wires (e.g. secondary to violent head tics) have been reported to date, the frequency of infectious complications (15-25\% across series) at the level of the battery, extension cables or surgical wound raised some concerns [73]. Stimulation-related events associated with thalamic DBS in 
GTS include sedation, abulia, fatigue, apathy, sexual dysfunction, and visual disturbances. Importantly, longitudinal observational studies showed that thalamic DBS may not lead to long-term adverse cognitive sequelae [74]. Anxiety with social avoidance, depression and hypomania have been reported slightly more with the GPi target, and overall resolved mainly with a course of pharmacological treatment. Dissociative and even psychotic symptoms have been exceptional occurrences, but threatening sufficiently to influence inclusion criteria and require very careful post-operative monitoring.

\section{Future directions}

Future research on DBS in GTS should first of all fulfill the need for active comparator trials. As patients with GTS may differ in response to treatment based on a particular comorbidity profile, larger, better powered trials would allow to adjust for the influence of comorbidities upon tic response to DBS. Although the crossover study design is by and large the most used, other designs, e.g. a delayed start design using blinded programming, might overcome the need to maintain stimulation parameters suboptimal in the blinded phase in order to guarantee masking [75]. With respect to outcome measures, existing trials showed that improvement of tic severity might not be paralleled by quality of life improvement. Databases and larger cohort studies would be crucial to assess long-term response, of which there is still very limited knowledge. The concept of closed loop DBS, which applies stimulation as a feedback to physiological changes (local field potentials at the target site, electric cortical activity, neurotransmitter concentrations), may be particularly suitable to the complex temporal dynamics of tics [76,77]. Finally, current directional steering by the use of the novel electrodes with a high number of contacts might improve the therapeutic window and help tailoring the treatment to the complex comorbidity profile of most patients with severe, medically refractory TS. 


\section{Conclusions}

Today, clinicians treating patients with GTS have a wide range of treatment options, ranging from psychotherapy and pharmacotherapy to neurosurgery. It is also worth noting that these approaches can be combined depending on the patient's status and needs. A major problem remains the lack of large, well designed and controlled studies to assess different treatment modalities due to the supposed rareness of the disease. Also, as is the case in much of medicine now, endpoint definition is under intense discussion, e.g. should outcome focus on tic reduction, psychosocial function or quality of life measures [78] ? Finally, despite not being discussed here, the multiple psychiatric comorbities in individuals with GTS make evaluation and patient satisfaction a challenging but important task. Nonetheless, there is cause for optimism as public interest for GTS is increasing and patient organizations across the globe strongly advocate the development of more targeted, better-tolerated and safer therapies [79]. 


\section{References}

1. American Psychiatric Association Diagnostic and statistical manual of mental disorders (5th ed.). Washington, DC, 2013.

2. Hirschtritt ME, Lee PC, Pauls DL, Dion Y, Grados MA, Illmann C, et al.; Tourette Syndrome Association International Consortium for Genetics. Lifetime prevalence, age of risk, and genetic relationships of comorbid psychiatric disorders in Tourette syndrome. JAMA Psychiatry 2015;72:325-33.

3. Martino D, Leckman J. Tourette Syndrome. Harvard University Press 2013.

4. Martino D, Cavanna A. Advances in the Neurochemistry and Neuropharmacology of Tourette Syndrome, 1st Edition. International Review of Neurobiology, Vol. 112. Academic Press, Cambridge, Massachusetts 2013.

5. Gilles de La Tourette G. Étude sur une affection nerveuse caractérisée par de l'incoordination motrice accompagnée d'écholalie et de coprolalie. Arch Neurol 1885;9:158-200.

6. Kushner HI. A Cursing Brain? The Histories of Tourette Syndrome. Harvard University Press 2000

7. Hartmann A, Worbe Y. Pharmacological treatment of Gilles de la Tourette syndrome. Neurosci Biobehav Rev 2013 ;37:1157-61.

8. Conelea CA, Woods DW, Zinner SH, Budman CL, Murphy TK, Scahill LD, et al. The impact of Tourette Syndrome in adults: results from the Tourette Syndrome impact survey. Community Ment Health J 2013;49:110-20.

9. Cath DC, Hedderly T, Ludolph AG, Stern JS, Murphy T, Hartmann A, et al.; ESSTS Guidelines Group. European clinical guidelines for Tourette syndrome and other tic disorders. Part I: assessment. Eur Child Adolesc Psychiatry. 2011 Apr;20(4):155-71.

10. Roessner V, Plessen KJ, Rothenberger A, Ludolph AG, Rizzo R, Skov L, et al.; ESSTS Guidelines Group. European clinical guidelines for Tourette syndrome and other tic disorders. Part II: pharmacological treatment. Eur Child Adolesc Psychiatry. 2011 Apr;20(4):173-96.

11. Verdellen C, van de Griendt J, Hartmann A, Murphy T; ESSTS Guidelines Group. European clinical guidelines for Tourette syndrome and other tic disorders. Part III: behavioural and psychosocial interventions. Eur Child Adolesc Psychiatry. 2011 Apr;20(4):197-207.

12. Müller-Vahl KR, Cath DC, Cavanna AE, Dehning S, Porta M, Robertson MM, et al.; ESSTS Guidelines Group. European clinical guidelines for Tourette syndrome and other tic disorders. Part IV: deep brain stimulation. Eur Child Adolesc Psychiatry. 2011 Apr;20(4):209-17.

13. McGuire JF, Ricketts EJ, Piacentini J, Murphy TK, Storch EA, Lewin AB. Behavior Therapy for Tic Disorders: An Evidenced-based Review and New Directions for Treatment Research. Curr Dev Disord Rep 2015;2:309-317.

14. Azrin NH, Nunn RG. Habit-reversal: A method of eliminating nervous habits and tics. Behaviour research and therapy 1973;11:619-28.

15. Piacentini J, Woods DW, Scahill L, Wilhelm S, Peterson AL, Chang S, et al. Behavior therapy for children with Tourette disorder: a randomized controlled trial. JAMA 2010;303:1929-37

16. Wilhelm S, Peterson AL, Piacentini J, Woods DW, Deckersbach T, Sukhodolsky DG, et al. Randomized trial of behavior therapy for adults with Tourette syndrome. Arch Gen Psychiatry 2012;69:795-803.

17. Verdellen CW, Keijsers GP, Cath DC, Hoogduin CA. Exposure with response prevention versus habit reversal in Tourettes's syndrome: a controlled study. Behav Res Ther 2004;42:501-11.

18. O'Connor KP, Brault M, Robillard S, Loiselle J, Borgeat F, Stip E. Evaluation of a cognitivebehavioural program for the management of chronic tic and habit disorders. Behav Res Ther 2001;39:667-81.

19. Morand-Beaulieu S, O'Connor KP, Sauvé G, Blanchet PJ, Lavoie ME. Cognitive-behavioral therapy induces sensorimotor and specific electrocortical changes in chronic tic and Tourette's disorder. Neuropsychologia 2015;79:310-21.

20. O'Connor K, St-Pierre-Delorme ME, Leclerc J, Lavoie M, Blais MT. Meta-cognitions in 
Tourette syndrome, tic disorders, and body-focused repetitive disorder. Can J Psychiatry 2014;59:417-25.

21. Storch EA, Morgan JE, Caporino NE, Brauer L, Lewin AB, Piacentini J, Murphy, TK. Psychosocial treatment to improve resilience and reduce impairment in youth with tics: an intervention case series of eight youth. J Cogn Psychother 2012:26:57-70.

22. McGuire JF, Arnold E, Park JM, Nadeau JM, Lewin AB, Murphy TK, et al. Living with tics: reduced impairment and improved quality of life for youth with chronic tic disorders. Psychiatry Res 2015;225:571-9.

23. Kahl KG, Winter L, Schweiger U. The third wave of cognitive behavioural therapies: what is new and what is effective? Curr Opin Psychiatry 2012;25:522-8.

24. Reese HE, Vallejo Z, Rasmussen J, Crowe K, Rosenfield E, Wilhelm S. Mindfulness-based stress reduction for Tourette Syndrome and Chronic Tic Disorder: a pilot study. J Psychosom Res 2015;78:293-8.

25. Franklin ME, Best SH, Wilson MA, Loew B, Compton SN. Habit reversal training and acceptance and commitment therapy for tourette syndrome: a pilot project. J Dev Phys Disabil 2011;23:49-60.

26. Himle MB, Freitag M, Walther M, Franklin SA, Ely L, Woods DW. A randomized pilot trial comparing videoconference versus face-to-face delivery of behavior therapy for childhood tic disorders. Behav Res Ther 2012;50:565-70.

27. Ricketts EJ, Goetz AR, Capriotti MR, Bauer CC, Brei NG, Himle MB, et al. A randomized waitlist-controlled pilot trial of voice over Internet protocol-delivered behavior therapy for youth with chronic tic disorders. J Telemed Telecare. 2015 Jul 13. pii: 1357633 X15593192. [Epub ahead of print]

28. Rowe J, Yuen HK, Dure LS. Comprehensive behavioral intervention to improve occupational performance in children with Tourette disorder. Am J Occup Ther 2013;67:194-200.

29. Ricketts EJ, Gilbert DL, Zinner SH, Mink JW, Lipps TD, Wiegand GA, et al. Pilot Testing Behavior Therapy for Chronic Tic Disorders in Neurology and Developmental Pediatrics Clinics. J Child Neurol 2015 Aug 13. pii: 0883073815599257. [Epub ahead of print]

30. Pringsheim T, Doja A, Gorman D, McKinlay D, Day L, Billinghurst L, et al. Canadian guidelines for the evidence-based treatment of tic disorders: pharmacotherapy. Can J Psychiatry 2012;57:133-43.

31. Rickards H, Cavanna AE, Worrall R. Treatment practices in Tourette syndrome: the European perspective. Eur J Paediatr Neurol 2012;16:361-4.

32. Müller-Vahl KR, Krueger D. Does Tourette syndrome prevent tardive dyskinesia? Mov Disord 2011;26:2442-3.

33. Hartmann A. Clinical pharmacology of nondopaminergic drugs in Tourette syndrome. Int Rev Neurobiol 2013;112:351-72.

34. Weisman H, Qureshi IA, Leckman JF, Scahill L, Bloch MH. Systematic review: pharmacological treatment of tic disorders--efficacy of antipsychotic and alpha-2 adrenergic agonist agents. Neurosci Biobehav Rev 2013;37:1162-71.

35. Farag M, Stern JS, Simmons H, Robertson MM. Serial pharmacological prescribing practices for tic management in Tourette syndrome. Hum Psychopharmacol 2015;30:435-41.

36. Hirose T, Kikuchi T. Aripiprazole, a novel antipsychotic agent: dopamine D2 receptor partial agonist. J Med Invest 2005;52:284-90.

37. Yoo HK, Joung YS, Lee JS, Song DH, Lee YS, Kim JW, et al. A multicenter, randomized, double-blind, placebo-controlled study of aripiprazole in children and adolescents with Tourette's disorder. J Clin Psychiatry;74:e772-80.

38. Masi G, Gagliano A, Siracusano R, Berloffa S, Calarese T, Ilardo G, et al. Aripiprazole in children with Tourette's disorder and co-morbid attention-deficit/hyperactivity disorder: a 12week, open-label, preliminary study. J Child Adolesc Psychopharmacol 2012;22:120-5

39. Rizzo R, Eddy CM, Calí P, Gulisano M, Cavanna AE. Metabolic effects of aripiprazole and pimozide in children with Tourette syndrome. Pediatr Neurol 2012;47:419-22.

40. Gilbert DL, Budman CL, Singer HS, Kurlan R, Chipkin RE. A D1 receptor antagonist, ecopipam, for treatment of tics in Tourette syndrome. Clin Neuropharmacol 2014;37:26-30.

41. Jankovic J, Jimenez-Shahed J, Brown LW. A randomised, double-blind, placebo-controlled 
study of topiramate in the treatment of Tourette syndrome. J Neurol Neurosurg Psychiatry 2010;81:70-3. doi:

42. Rath JJ, Tavy DL, Wertenbroek AA, van Woerkom TC, de Bruijn SF. Botulinum toxin type A in simple motor tics: short-term and long-term treatment-effects. Parkinsonism Relat Disord 2010;16:478-81.

43. Müller-Vahl KR. Treatment of Tourette syndrome with cannabinoids. Behav Neurol 2013;27:119-24.

44. Whiting PF, Wolff RF, Deshpande S, Di Nisio M, Duffy S, Hernandez AV, et al. Cannabinoids for Medical Use: A Systematic Review and Meta-analysis. JAMA 2015;313:2456-73.

45. Scharf JM, Miller LL, Gauvin CA, Alabiso J, Mathews CA, Ben-Shlomo Y. Population prevalence of Tourette syndrome: a systematic review and meta-analysis. Mov Disord 2015;30:221-8.

46. Kalanithi PS, Zheng W, Kataoka Y, DiFiglia M, Grantz H, Saper CB, et al. Altered parvalbumin-positive neuron distribution in basal ganglia of individuals with Tourette syndrome. Proc Natl Acad Sci U S A 2005;102:13307-12.

47. Kataoka Y, Kalanithi PS, Grantz H, Schwartz ML, Saper C, Leckman JF, Vaccarino FM. Decreased number of parvalbumin and cholinergic interneurons in the striatum of individuals with Tourette syndrome. J Comp Neurol 2010;518:277-91.

48. Cubo E, Fernández Jaén A, Moreno C, Anaya B, González M, Kompoliti K. Donepezil use in children and adolescents with tics and attention-deficit/hyperactivity disorder: an 18-week, single-center, dose-escalating, prospective, open-label study. Clin Ther 2008;30:182-9.

49. Ganos C, Hartmann A. Altered cholinergic neurotransmission in Tourette syndrome. Mov Disord 2015;30:638.

50. Bortolato M, Frau R, Godar SC, Mosher LJ, Paba S, Marrosu F, Devoto P. The implication of neuroactive steroids in Tourette's syndrome pathogenesis: A role for $5 \alpha$-reductase? J Neuroendocrinol 2013;25:1196-208.

51. Muroni A, Paba S, Puligheddu M, Marrosu F, Bortolato M. A preliminary study of finasteride in Tourette syndrome. Mov Disord 2011;26:2146-7.

52. Singer HS, Morris C, Grados M. Glutamatergic modulatory therapy for Tourette syndrome. Med Hypotheses 2010;74:862-7.

53. Lemmon ME, Grados M, Kline T, Thompson CB, Ali SF, Singer HS. Efficacy of Glutamate Modulators in Tic Suppression: A Double-Blind, Randomized Control Trial of D-serine and Riluzole in Tourette Syndrome. Pediatr Neurol 2015;52:629-34.

54. Cox JH, Seri S, Cavanna AE. Histaminergic modulation in Tourette syndrome. Expert Opin Orphan Drugs. $2016 ; 4$ :205-203.

55. Ercan-Sencicek AG, Stillman AA, Ghosh AK, Bilguvar K, O'Roak BJ, Mason CE, et al. Lhistidine decarboxylase and Tourette's syndrome. N Engl J Med 2010;362:1901-8.

56. Karagiannidis I, Dehning S, Sandor P, Tarnok Z, Rizzo R, Wolanczyk T, et al. Support of the histaminergic hypothesis in Tourette syndrome: association of the histamine decarboxylase gene in a large sample of families. J Med Genet 2013;50:760-4.

57. Castellan Baldan L, Williams KA, Gallezot JD, Pogorelov V, Rapanelli M, Crowley M, et al. Histidine decarboxylase deficiency causes tourette syndrome: parallel findings in humansand mice. Neuron 2014;81:77-90.

58. Dauvilliers Y, Bassetti C, Lammers GJ, Arnulf I, Mayer G, Rodenbeck A, et al.; HARMONY I study group. Pitolisant versus placebo or modafinil in patients with narcolepsy: a doubleblind, randomised trial. Lancet Neurol. 2013;12:1068-75.

59. Hartmann A, Worbe Y, Arnulf I. Increasing histamine neurotransmission in Gilles de la Tourette syndrome. J Neurol $2012 ; 259: 375-6$.

60. Rapanelli M, Pittenger C. Histamine and histamine receptors in Tourette syndrome and other neuropsychiatric conditions. Neuropharmacology 2015 Aug 14. pii: S0028-3908(15)30065-4.

61. Schrock LE, Mink JW, Woods DW, Porta M, Servello D, Visser-Vandewalle V, Silburn PA, et al.; Tourette Syndrome Association International Deep Brain Stimulation (DBS) Database and Registry Study Group. Tourette syndrome deep brain stimulation: a review and updated recommendations. Mov Disord 2015;30:448-71 
62. Motlagh MG, Smith ME, Landeros-Weisenberger A, Kobets AJ, King RA, Miravite bJ, et al. Lessons Learned from Open-label Deep Brain Stimulation for Tourette Syndrome: Eight Cases over 7 Years. Tremor Other Hyperkinet Mov 2013 1;3. pii:tre-03-170-4428-1.

63. Maciunas RJ, Maddux BN, Riley DE, Whitney CM, Schoenberg MR, Ogrocki PJ, et al. Prospective randomized double-blind trial of bilateral thalamic deep brain stimulation in adults with Tourette syndrome. J Neurosurg 2007;107:1004-14.

64. Ackermans L, Duits A, van der Linden C, Tijssen M, Schruers K, Temel Y, et al. Doubleblind clinical trial of thalamic stimulation in patients with Tourette syndrome. Brain 2011;134:832-44.

65. Kefalopoulou Z, Zrinzo L, Jahanshahi M, Candelario J, Milabo C, Beigi M, et al. Bilateral globus pallidus stimulation for severe Tourette's syndrome: a double-blind, randomised crossover trial. Lancet Neurol 2015;14:595-605.

66. Sachdev PS, Mohan A, Cannon E, Crawford JD, Silberstein P, Cook R, et al. Deep brain stimulation of the antero-medial globus pallidus interna for Tourette syndrome. PLoS One 2014 19;9(8):e104926.

67. Servello D, Sassi M, Brambilla A, Porta M, Haq I, Foote KD, Okun MS. De novo and rescue DBS leads for refractory Tourette syndrome patients with severe comorbid OCD: a multiple case report. J Neurol 2009;256:1533-9.

68. Servello D, Zekaj E, Saleh C, Lange N, Porta M. Deep Brain Stimulation in Gilles de la Tourette Syndrome: What Does the Future Hold? A Cohort of 48 Patients. Neurosurgery 2016;78:91-100.

69. Porta M, Servello D, Zanaboni C, Anasetti F, Menghetti C, Sassi M, et al. Deep brain stimulation for treatment of refractory Tourette syndrome: long-term follow-up. Acta Neurochir (Wien) 2012;154:2029-41.

70. Piedimonte F, Andreani JC, Piedimonte L, Graff P, Bacaro V, Micheli F, et al. Behavioral and motor improvement after deep brain stimulation of the globus pallidus externus in a case of Tourette's syndrome. Neuromodulation 2013;16:55-8.

71. Martinez-Torres I, Hariz MI, Zrinzo L, Foltynie T, Limousin P. Improvement of tics after subthalamic nucleus deep brain stimulation. Neurology 2009;72:1787-9.

72. Tremblay L, Worbe Y, Thobois S, Sgambato-Faure V, Féger J. Selective dysfunction of basal ganglia subterritories: From movement to behavioral disorders. Mov Disord 2015;30:1155-70.

73. Servello D, Sassi M, Gaeta M, Ricci C, Porta M. Tourette syndrome (TS) bears a higher rate of inflammatory complications at the implanted hardware in deep brain stimulation (DBS). Acta Neurochir (Wien) 2011;153:629-32.

74. Porta M, Brambilla A, Cavanna AE, Servello D, Sassi M, Rickards H, et al. Thalamic deep brain stimulation for treatment-refractory Tourette syndrome: two-year outcome. Neurology 2009;27;73:1375-80.

75. Jimenez-Shahed J. Design challenges for stimulation trials of Tourette's syndrome. Lancet Neurol 2015;14:563-5.

76. Okun MS, Foote KD, Wu SS, Ward HE, Bowers D, Rodriguez RL, et al. A trial of scheduled deep brain stimulation for Tourette syndrome: moving away from continuous deep brain stimulation paradigms. JAMA Neurol 2013;70:85-94.

77. Almeida L, Martinez-Ramirez D, Rossi PJ, Peng Z, Gunduz A, Okun MS. Chasing tics in the human brain: development of open, scheduled and closed loop responsive approaches to deep brain stimulation for tourette syndrome. J Clin Neurol 2015;11:122-31.

78. Evans J, Seri S, Cavanna AE. The effects of Gilles de la Tourette syndrome and other chronic tic disorders on quality of life across the lifespan: a systematic review. Eur Child Adolesc Psychiatry. 2016 Feb 15. [Epub ahead of print]

79. Rickards H, Paschou P, Rizzo R, Stern JS. A brief history of the European Society for the Study of Tourette Syndrome Behav Neurol 2013;27:3-5. 


\section{BOX 1}

\section{Selection criteria for DBS [60]}

DSM-5 diagnosis of GTS by expert clinician

$>$ Tic severity high (proposal: > 35 on Yale Global Tic Severity Scale, severity subscore) and tics prominent feature and cause of disability

$>$ Tics refractory to conservative therapy ( 3 classes of medications + behavioural therapy)

$>$ Stable and optimised treatment of medical, cognitive and behavioural comorbidities for 6 months

$>$ Expected compliance during monitoring (stable psychosocial environment)

$>$ Neuropsychological profile indicating that candidate can tolerate surgery, post-operative follow-up, and possibility of poor outcome

Local ethics committee involvement for cases involving patients $<18$ years and for "urgent" cases 